\title{
OBSERVATIONS ON THE INTESTINAL CARRIAGE OF PSEUDOMONAS AERUGINOSA
}

\author{
B. J. Stoodley* and B. T. Thom $\dagger$ \\ Department of Bacteriology, St Bartholomew's Hospital, London and \\ Cross-Infection Reference Laboratory, Colindale, London
}

PSEUDOMONASAERUGINOSA is one of the more troublesome organisms causing sepsis acquired in hospital. Outbreaks of infection may occur as a result of direct implantation of organisms from a common source into such sites as the eye, bladder or lung. In a general hospital ward, the sporadic infections with $P$ s. aeruginosa that occur are usually due to different strains. The source and route of infection in these incidents are difficult to trace.

One possible source of infection is the patient who is a carrier of Pseudomonas aeruginosa, and examples of possible autogenous infection have been described. Gould and McLeod (1960), in a study of the possible sources of Ps. aeruginosa responsible for urinary infection, isolated the organism from rectal swabs of seven patients who later developed infections. The strains isolated from the urine were identical with the bowel strains in each of three patients. Darrell and Wahba (1964) described one patient with chest infection and another with tracheostomy wound infection, in which the strains of Ps. aeruginosa involved were indistinguishable from those that had been isolated previously from rectal swabs of the respective patients. Shooter et al. (1966) investigated 12 strains of Ps. aeruginosa from ten lesions occurring in patients in a surgical ward; strains indistinguishable from eight of the $12 \mathrm{had}$ been detected in samples of faeces of the respective patients taken before infection occurred. Sutter and Hurst (1966) observed 14 patients with severe burns; 12 of them developed infections with Ps. aeruginosa, and three acquired the organism in the bowel first.

The frequency with which Ps. aeruginosa can be isolated from the bowel is greater in patients in hospital and is considerably influenced by the methods of culture employed. Lowbury and Fox (1954) isolated Ps. aeruginosa from 3.2 per cent. of 2993 out-patients with gastro-intestinal symptoms by plating faecal specimens on cetrimide agar. Darrell and Wahba examined rectal swabs and found that direct plating on MacConkey agar was unsatisfactory for the isolation of Ps. aeruginosa, but that incubation in selenite broth with subculture on cetrimide agar was satisfactory; $3 \cdot 5$ per cent of 426 patients carried the organism on admission to hospital and a further 5 per cent. acquired it while in hospital. Shooter et al. found Ps. aeruginosa in only four of 71 healthy adults, but in 24 per cent. of 108 patients examined within 2 days of admission to a surgical ward, and in 38 per cent. at some time during their stay in the ward. These authors examined three emulsified samples of each faecal specimen by primary culture on cetrimide agar, and by enrichment in cetrimide broth with subculture on cadmium sulphate agar. Grogan (1966) isolated the organism from the faeces of 19 ( 23 per cent.) of 81 in-patients by means of enrichment in cetrimide broth and subculture on cetrimide agar. Sutter, Hurst and Lane (1967) examined faeces of healthy adults by enrichment in Drake's medium (Drake, 1966) and found 11.9 per cent. of 235 to be carriers.

Most observations on the carriage rate of Ps. aeruginosa have been concerned with isolation from the faeces, although Shooter et al. reported isolations from ileostomies,

Received 20 Aug. 1969; accepted 19 Dec. 1969.

* Present address: St Mark's Hospital, City Road, London, E.C.1, and + Public Health Laboratory, Whipps Cross Hospital, London, E.11.

J. MED. MICROBIOL.-VOL. 3 (1970) 
colostomies and caecostomies. McLeod (1958) cultured intestinal contents from seven cadavers and isolated Ps. aeruginosa from one of them.

We undertook the present investigation into intestinal carriage of Ps. aeruginosa with the following purposes: to compare the incidence of carriage at different levels of the bowel; to see whether carriage in the proximal bowel might explain the known high incidence in patients with ileostomies and also the intermittency of faecal carriage in hospital patients; to study factors that might influence carriage of Ps. aeruginosa in patients in hospital; and to confirm that the incidence of carriage is low in normal people and out-patients. Information on the sensitivity of the methods of isolation employed was also sought (Stoodley, unpublished).

\section{MATERIALS AND METHODS}

Collection of specimens

Necropsy series. Samples of intestinal contents were collected from 100 cadavers between December 1966 and January 1967, and between April 1967 and June 1967. All necropsies performed during the two periods of time were included, with the exception of four in which the gastro-intestinal tract could not be removed without contamination of the contents.

A ligature was placed at the ileocaecal junction, and the intestines were removed from the body. Samples were taken from the following parts of the intestine, when they were present: jejunum, terminal ileum, caecum and sigmoid colon; three patients had had some of the sites removed at operation. The site for incision was dipped into tincture of iodine (B.P.) and an incision made in the anti-mesenteric border with a flame-sterilised blade. The contents were expressed from each site into a clean waxed carton. Suspensions of intestinal contents were made by transferring about $2.5 \mathrm{~g}$ into each of three sterile screwcapped bottles containing $2.5 \mathrm{ml}$ of normal saline and shaking with a mechanical shaker.

Ileostomy fluid. This was collected into a screw-capped bottle from each of 108 people attending an Ileostomy Association meeting. It was examined directly from the bottle in which it had been collected; three samples were taken from each bottle for culture.

Faeces. We examined samples of faeces from 240 hospital in-patients and 103 outpatients; these samples had been sent to the routine laboratory mainly for the investigation of diarrhoeal diseases. Samples were also examined from 50 normal persons without gastro-intestinal symptoms who had applied for work in the hospital Catering Department. A single portion of each stool was cultured.

\section{Bacteriology}

Separate throat swabs were soaked in the suspensions of the intestinal contents and three throat swabs were soaked in each ileostomy fluid specimen. The soaked swabs were plated out on a plate of nutrient agar containing 0.03 per cent. cetrimide and then each swab was placed into broth containing 0.02 per cent. cetrimide. The broth cultures were subcultured next day by using the same swabs and replating them on cetrimide agar plates. All cultures were incubated for $18-24 \mathrm{hr}$ at $37^{\circ} \mathrm{C}$. The primary plates were left overnight on the bench after incubation, and the three primary and three secondary plates for each specimen were examined together. The number of colonies on the primary plates was recorded as (i) less than 10 colonies per plate, (ii) between 10 and 100 per plate, or (iii) more than 100 per plate. About $2.5 \mathrm{~g}$ of faeces from each of the patients and from the normal persons was placed directly into a tube of cetrimide broth and, after overnight incubation at $37^{\circ} \mathrm{C}$, a large loopful of broth was subcultured on a cetrimide agar plate on each occasion. The plates were examined after overnight incubation and growth was recorded as either positive or negative; no colony counts were done. 
Blue-green or red pigmented colonies giving a rapid oxidase reaction (Kovacs, 1956) were accepted as Ps. aeruginosa. Non-pigmented, oxidase-positive colonies, with or without demonstrable fluorescence, were considered to be Ps. aeruginosa if they were composed of Gram-negative, motile rods that produced slime and a reducing substance in gluconate broth (Haynes, 1951) and survived three successive subcultures at $42^{\circ} \mathrm{C}$ (Haynes and Rhodes, 1962), or if they were agglutinated in a slide-test by a polyvalent $P$ s. aeruginosa O-antiserum (Wahba, 1965).

TABLE I

Factors influencing the frequency of isolation of Pseudomonas aeruginosa from samples of intestinal contents at necropsy

\begin{tabular}{|c|c|c|c|}
\hline $\begin{array}{c}\text { Details of patient from } \\
\text { whom sample was obtained }\end{array}$ & $\begin{array}{l}\text { Number of } \\
\text { patients examined }\end{array}$ & $\begin{array}{l}\text { Number } \\
\text { positive* }\end{array}$ & $\begin{array}{l}\text { Percentage } \\
\text { positive }\end{array}$ \\
\hline $\begin{array}{llll}\text { Male } & \cdot & \cdot & \cdot \\
\text { Female } & \cdot & \cdot & \cdot\end{array}$ & $\begin{array}{l}53 \\
47\end{array}$ & $\begin{array}{l}19 \\
17\end{array}$ & $\begin{array}{l}35 \cdot 9 \\
36 \cdot 1\end{array}$ \\
\hline $\begin{array}{l}\text { Aged less than } 30 \mathrm{yr} \text {. } \\
\text { Aged } 30-60 \mathrm{yr} \\
\text { Aged more than } 60 \mathrm{yr}\end{array}$ & $\begin{array}{l}14 \\
34 \\
52\end{array}$ & $\begin{array}{r}4 \\
11 \\
21\end{array}$ & $\begin{array}{l}28 \cdot 6 \\
32 \cdot 3 \\
40 \cdot 4\end{array}$ \\
\hline $\begin{array}{l}\text { From medical ward } . \\
\text { From surgical ward } .\end{array}$ & $\begin{array}{l}60 \\
40\end{array}$ & $\begin{array}{l}20 \\
16\end{array}$ & $\begin{array}{l}33 \cdot 3 \\
40 \cdot 0\end{array}$ \\
\hline $\begin{array}{l}\text { Stay in ward: } \\
\text { Less than } 1 \text { day } \\
1-7 \text { days } \\
7-28 \text { days } \\
\text { More than } 28 \text { days }\end{array}$ & $\begin{array}{r}8 \\
22 \\
41 \\
29\end{array}$ & $\begin{array}{r}2 \\
10 \\
12 \\
12\end{array}$ & $\begin{array}{l}25 \cdot 0 \\
45 \cdot 5 \\
29 \cdot 2 \\
41 \cdot 4\end{array}$ \\
\hline $\begin{array}{l}\text { Received oral antibiotics } \\
\text { Received no oral antibiotics }\end{array}$ & $\begin{array}{l}44 \\
56\end{array}$ & $\begin{array}{l}19 \\
17\end{array}$ & $\begin{array}{l}43 \cdot 2 \\
30 \cdot 4\end{array}$ \\
\hline
\end{tabular}

* I.e., the number of samples that yielded Pseudomonas aeruginosa on culture.

In the post-mortem survey, when Ps. aeruginosa was isolated from more than one site, one colony from each site was typed, and, in addition, a representative of each distinct colonial form from each site was typed.

\section{Typing of Ps. aeruginosa}

Phage-typing. The method has been described previously (Shooter et al.). Two additional phages isolated at the Central Public Health Laboratory, Colindale, were included.

Serological typing. Antisera were prepared against the following strains, types 1-12 (Habs, 1957), type II (Sandvik, 1960), type 14 (Wahba), and subtypes 2b and 5d (Véron, 1961). Isolates were typed by slide agglutination tests.

\section{RESULTS}

\section{Isolation of Pseudomonas aeruginosa from intestinal contents at necropsy}

Ps. aeruginosa was isolated from one or more sites in the intestinal tracts of 36 of the 100 cadavers (table I). It was obtained from an equal number of 
males and females, more often in patients over the age of $60 \mathrm{yr}$ (40 per cent.), than in younger patients ( 30 per cent.), and more often in surgical ( 40 per cent.) than in medical patients ( 33 per cent.). The organism was present more often in those who had received oral antibiotics ( 43 per cent.) than in those who had not (30 per cent). There was no evidence of a steep rise in carriage-rate during stay in hospital, and one-third or more of the patients appeared to have been colonised at all stages of their stay. Two out of eight patients who had been in hospital for less than $24 \mathrm{hr}$ had Ps. aeruginosa in their gut post mortem,

TABLE II

The isolation of Pseudomonas aeruginosa from different intestinal sites in 100 cadavers at necropsy

\begin{tabular}{|c|c|c|c|c|}
\hline \multirow{2}{*}{ Number of patients } & \multicolumn{4}{|c|}{$\begin{array}{l}\text { Ps. aeruginosa isolated }(+) \text { or not isolated } \\
(-) \text { from sample taken from }\end{array}$} \\
\hline & jejunum & ileum & caecum & $\begin{array}{l}\text { sigmoid } \\
\text { colon }\end{array}$ \\
\hline $\begin{array}{c}8^{*} \\
2 \\
1 \dagger \\
5 \\
1 \\
4 \\
5 \\
6 \\
4 \\
64\end{array}$ & $\begin{array}{l}+ \\
+ \\
+ \\
= \\
= \\
= \\
= \\
= \\
-\end{array}$ & $\begin{array}{l}+ \\
+ \\
+ \\
+ \\
+ \\
+ \\
\pm \\
= \\
-\end{array}$ & $\begin{array}{l}+ \\
\pm \\
+ \\
+ \\
\pm \\
+ \\
+ \\
+ \\
-\end{array}$ & $\begin{array}{l} \pm \\
\pm \\
+ \\
\pm \\
\pm \\
+ \\
\pm \\
\pm \\
-\end{array}$ \\
\hline Total: 100 & 11 & 21 & 26 & 23 \\
\hline
\end{tabular}

but one of them had recently been in hospital. Ten of the 19 patients who had undergone gastro-intestinal surgery yielded the organism at necropsy; these included six of nine who had had only colonic surgery.

The frequency with which Ps. aeruginosa was isolated from each of the four intestinal sites (see Methods) is shown in table II. Ps. aeruginosa was isolated from all sites in eight instances, and from a single site in 14 instances. When the organism was isolated from more than one site, the positive sites were nearly always adjacent. Thus in the seven instances in which three sites were positive they were all adjacent, and in six of the seven instances in which two sites were positive the positive sites were adjacent. The total number of isolates for each site was as follows: jejunum 11 , ileum 21 , caecum 26 , sigmoid colon 23.

The results of typing the strains isolated from different sites are shown in table III. It is our practice to consider strains distinguishable if they belong to different serotypes, whatever the phage-typing pattern, or if they belong to the 
same serotype but have widely differing phage-typing patterns. In this investigation, however, all the strains finally considered to be distinguishable belonged

TABLE III

Distinguishable strains of Pseudomonas aeruginosa present in the intestinal tract of the same patient

\begin{tabular}{|c|c|c|c|c|c|c|}
\hline \multirow{2}{*}{$\begin{array}{l}\text { Patient } \\
\text { number }\end{array}$} & \multirow{2}{*}{$\begin{array}{c}\text { Number } \\
\text { of } \\
\text { sites } \\
\text { positive }\end{array}$} & \multirow{2}{*}{$\begin{array}{l}\text { Total number } \\
\text { of } \\
\text { distinguishable } \\
\text { strains isolated }\end{array}$} & \multicolumn{4}{|c|}{ Distinct strains* present in } \\
\hline & & & jejunum & ileum & caecum & $\begin{array}{c}\text { sigmoid } \\
\text { colon }\end{array}$ \\
\hline $\begin{array}{l}1 \\
2 \\
3 \\
4 \\
5 \\
6 \\
7\end{array}$ & $\begin{array}{l}4 \\
4 \\
3 \\
3 \\
3 \\
2 \\
1\end{array}$ & $\begin{array}{c}4 \\
3 \\
2 \\
2 \\
2 \\
2 \text { or } 3 \\
\quad 2\end{array}$ & $\begin{array}{l}\text { A } \\
\text { A } \\
\cdots \\
\cdots \\
\cdots \\
\cdots \\
\cdots\end{array}$ & $\begin{array}{c}\text { B } \\
\text { A } \\
\text { A } \\
\text { A } \\
\mathrm{A}, \mathrm{B} \dagger \\
\ldots \\
\cdots\end{array}$ & $\begin{array}{c}\mathbf{B} \\
\mathbf{B} \\
\mathbf{B} \\
\mathbf{B} \\
\mathbf{A} \\
\begin{array}{c}\mathbf{A}, \mathbf{A}_{1}^{\ddagger} \\
\mathbf{A}, \mathbf{B}+\end{array}\end{array}$ & $\begin{array}{c}\text { C, D } \\
\text { C } \\
\text { A } \\
\text { A } \\
\text { A } \\
\text { A } \\
\cdots\end{array}$ \\
\hline
\end{tabular}

* Separately coded A, B, C, D for each patient; $\ldots=$ no strain isolated.

$\dagger$ More than one distinct strain isolated.

$\ddagger$ Relationship of strain $A$ to strain $A_{1}$ not certain.

TABLE IV

Isolation of Pseudomonas aeruginosa (i) from specimens of faeces submitted as a routine, (ii) from faeces of normal persons, and (iii) from ileostomy fluids

\begin{tabular}{l|c|c|c}
\hline $\begin{array}{c}\text { Details of person from } \\
\text { whom sample was taken }\end{array}$ & $\begin{array}{c}\text { Number of } \\
\text { samples examined }\end{array}$ & $\begin{array}{c}\text { Number } \\
\text { positive* }\end{array}$ & $\begin{array}{c}\text { Percentage } \\
\text { positive }\end{array}$ \\
\hline $\begin{array}{l}\text { In-patient } \\
\text { with formed stool }\end{array}$ & 134 & 24 & 17.9 \\
with loose stool . & 106 & 20 & $18 \cdot 8$ \\
$\begin{array}{l}\text { Out-patient } \\
\text { with formed stool } \\
\text { with loose stool . }\end{array}$ & 61 & 5 & 8.2 \\
Normal person. & 42 & 9 & $21 \cdot 4$ \\
Ileostomy patient & 50 & 2 & 4.0 \\
\hline
\end{tabular}

* I.e., number yielding Ps. aeruginosa on culture.

to different serotypes. Serious difficulty in assessing the relationship between strains was experienced with only one pair of cultures; three colonially distinct organisms were isolated from the caecum of patient no. 6 . One of these was distinct (B). The other strains were a serotype 1 and a poly-agglutinable organism; the phage-typing patterns were rather similar.

In all, seven of the 36 cadavers from which Ps. aeruginosa was isolated yielded two or more distinct strains (table III); in this group, one patient 
had four distinct strains, and one (or two) patients had three distinct strains. On four occasions, two or more distinct strains were isolated from the same site. No site appeared to favour colonisation by a particular strain.

TABLE V

Effect of sampling three specimens from each intestinal site

\begin{tabular}{l|c|c|c|c}
\hline $\begin{array}{c}\text { Proportion of } \\
\text { replicate } \\
\text { specimens } \\
\text { yielding } \\
\text { Ps. aeruginosa }\end{array}$ & \multicolumn{2}{|c|}{$\begin{array}{c}\text { Samples giving positive result } \\
\text { on primary plate }\end{array}$} & \multicolumn{2}{|c}{$\begin{array}{c}\text { Samples giving positive result } \\
\text { after enrichment }\end{array}$} \\
\hline 3 of 3 & Number & $\begin{array}{c}\text { Number negative } \\
\text { after enrichment }\end{array}$ & Number & $\begin{array}{c}\text { Number negative } \\
\text { on primary plate }\end{array}$ \\
\hline 2 of 3 & 56 & 0 & 55 & 0 \\
1 of 3 & 4 & 0 & 5 & 2 \\
\hline Total positive & 12 & 4 & 16 & 6 \\
\hline
\end{tabular}

Isolation of Ps. aeruginosa from living patients and normal people

The frequency of isolation of Ps. aeruginosa from the faeces of in-patients, out-patients and normal people, and from ileostomy fluids, is shown in table IV. Ps. aeruginosa was isolated more frequently from faeces of patients with symptoms of gastro-intestinal disease than from faeces of normal individuals.

\section{TABLE VI}

The relation of the number of colonies cultured on primary plates from intestinal contents to the success of enrichment culture

\begin{tabular}{c|c|c|c}
\hline $\begin{array}{c}\text { Number of colonies } \\
\text { on primary plate }\end{array}$ & $\begin{array}{c}\text { Number of primary plates } \\
\text { bearing the stated number } \\
\text { of colonies }\end{array}$ & $\begin{array}{c}\text { Number of samples giving } \\
\text { the stated result on } \\
\text { enrichment culture }\end{array}$ \\
\cline { 2 - 3 }$>100$ & 127 & 3 & 124 \\
$11-100$ & 25 & 4 & 21 \\
$1-10$ & 36 & 8 & 28 \\
0 & 997 & 979 & 18 \\
\hline
\end{tabular}

It was present more frequently in loose than in formed stools. The incidence in ileostomy fluids was significantly greater than that in loose stools or in ileal contents examined at necropsy. 


\section{Sensitivity of isolation methods}

The results of examining three samples from each of the necropsy specimens by direct plating and by enrichment are shown in table V. In all, 395 sites were sampled and 72 were positive for $P$ s. aeruginosa on direct plating; 76 were positive after enrichment. Material cultured from 56 of 72 sites positive on direct plating yielded the organism in all three of the test plates. Of 216 primary plates seeded from the 72 positive sites, 188 were positive, so that if one instead of three plates had been used, the number of successful isolates would have been reduced from 72 to $62 \cdot 7$. Similarly, 76 sites were positive on enrichment culture, but the number would have been 63.7 if one enrichment culture only had been made. The numbers of colonies of $P$ s. aeruginosa present on primary culture plates seeded with intestinal contents, as described in the Methods section, are given in table VI. There were more than 100 colonies on each of 127 of 186 positive direct plates. The success of isolation after incubation in cetrimide broth was clearly related to the numbers of Ps. aeruginosa in the original inoculum. When there were ten or fewer colonies on the direct plate, only 72 per cent. ( 26 of 36 ) of the corresponding enrichment cultures were positive. When direct plates were negative, less than 2 per cent. (18 of 997) of the enrichment cultures were positive.

\section{Discussion}

Culture of intestinal contents at necropsy confirmed that a high proportion of patients in hospital harbour Pseudomonas aeruginosa in the bowel. This organism was isolated with similar frequency from the ileum, caecum and sigmoid colon, and less frequently from the jejunum. However, in 12 cases Ps. aeruginosa was not isolated from the sigmoid colon but was isolated from other sites. This suggests that a single negative stool examination cannot be relied upon as an indication that a patient is not carrying the organism.

When Ps. aeruginosa was isolated from only two or three of the sites examined, the positive sites were adjacent in all but one instance. This could be due to the passage of ingested strains through the bowel.

The frequency of isolation of Ps. aeruginosa from the faeces of people without gastro-intestinal symptoms was similar to that found in previous studies. We isolated the organism from 18.3 per cent. of patients in hospital, whereas the comparable isolation rate reported by Shooter et al. (1966) was 24 per cent. and we found the organism in the sigmoid colon of 23 per cent. of cadavers in the present series of necropsies. The difference can be partly explained by the methods of sampling used.

The examination by direct plating of three specimens from each intestinal site in the post-mortem series demonstrated the presence of the organism in 72 sites, compared with an estimated 62.7 if a single specimen had been examined. From our quantitative studies on $P$ s. aeruginosa in intestinal contents, it appears that increasing the number of direct plate cultures is as effective as employing enrichment cultures in increasing the number of successful isolations. Culture in cetrimide broth is a selective procedure, but is not very 
efficient in the detection of small numbers of organisms. It is possible that the carrier of large numbers of pseudomonas organisms is of greater significance as a source of infection, and such a carrier is likely to be detected by direct plating of faeces or intestinal contents.

Persons with ileostomies, who were living a normal life outside hospital, were shown to have a high rate of carriage of Ps. aeruginosa. The incidence of 73 per cent. in the present study is similar to that found by Shooter et al. for patients in hospital with a colostomy, ileostomy or caecostomy. The high incidence in ileostomy fluid may be due to contamination of the ileostomy bag, or to some abnormality in the ileum of these patients, because we found a much lower incidence in the ileal contents taken at necropsy. Whatever the reason for the high carriage rate, patients with enterostomies should be regarded as potential sources of cross-infection.

There is evidence that patients with infection due to Ps. aeruginosa may derive the organism from their own bowel, and it is also possible that treatment of established infections may sometimes be ineffective because of continuous re-infection from the bowel. It might therefore be possible to protect patients by identifying those who are carriers and giving oral therapy pre-operatively.

\section{SUMMARY}

Intestinal contents obtained at necropsy from 100 patients, 99 of whom died while in hospital, were examined for Ps. aeruginosa. The contents were taken from four sites; the organism was isolated from all sites in eight patients. The over-all carriage rate was 36 per cent., but the rate was increased to 43.2 per cent. if oral antibiotics had been administered, and to 52.6 per cent. if gastro-intestinal surgery had been performed.

Ps. aeruginosa was isolated from the faeces of 13.6 per cent. of 103 outpatients, 18.3 per cent. of 240 in-patients and 4 per cent. of 50 normal persons, and from 73 per cent. of 108 ileostomy fluid specimens.

The sampling method for detecting intestinal carriers of Ps. aeruginosa is discussed.

We would like to thank Dr A. G. Stansfield and the Staff of the Morbid Anatomy Department for their assistance, the Secretary and Members of the Ileostomy Association for their kind co-operation, Mr D. Greenwood for technical assistance, Mrs Juliet F. Bullimore for phage-typing, Dr Elizabeth $\mathbf{H}$. Asheshov for assistance in interpreting the results of phagetyping and Dr M. T. Parker and Professor R. A. Shooter for their encouragement.

Darrell, J. H., and Wahba, A. H. DRAKE, C. $\mathrm{H}$.

Gould, J. C., AND McLeOd, J. W. Grogan, J. B.

HABS, I.

HAYNES, W. C. . . .

Haynes, W. C., and Rhodes, L. J. Kovacs, $N$.

Lowbury, E. J. L., AND Fox, J. E.

\section{REFERENCES}

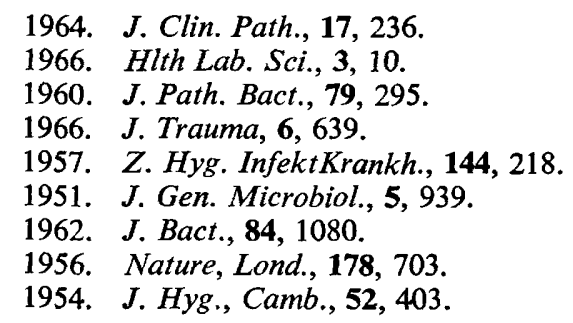


MCLEOD, J. W.

SANDVIK, $O$.

SHOOTER, R. A., WALKer, K. A., Williams, V. R., Horgan, Gillian M., Parker, M. T., Asheshov, ElizaBETH H., AND Bullimore, Juliet F.

SUTTER, Vera L., AND HURST, Valeri SutTer, Vera L., Hurst, Valerie, aNd LANE, C. W.

VÉron, M.

WAHBA, A. H.
1958. Lancet, 1, 394.

1960. Acta path. microbiol. scand., 48, 56.

1966. Lancet, 2, 1331.

1966. Ann. Surg., 163, 597.

1967. Hlth Lab. Sci., 4, 245.

1961. Annls Inst. Pasteur, Paris, 101, 45.

1965. Br. Med. J., 1, 86. 